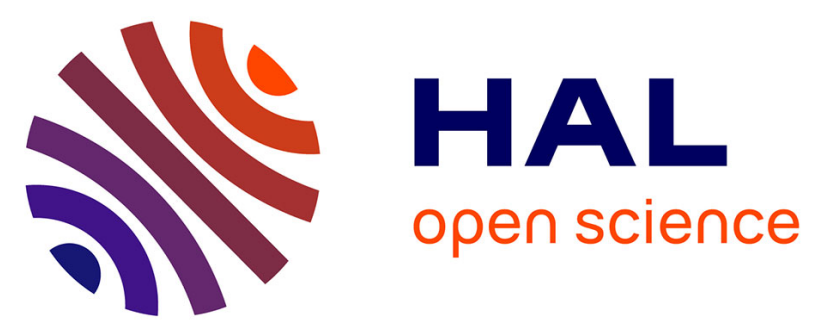

\title{
Numerical study of laser ablation on aluminum for shock-wave applications: development of a suitable model by comparison with recent experiments
}

Simon Bardy, Bertrand Aubert, Laurent Berthe, Patrick Combis, David Hébert, Emilien Lescoute, Jean-Luc Rullier, Laurent Videau

\section{To cite this version:}

Simon Bardy, Bertrand Aubert, Laurent Berthe, Patrick Combis, David Hébert, et al.. Numerical study of laser ablation on aluminum for shock-wave applications: development of a suitable model by comparison with recent experiments. Optical Engineering, 2017, 56 (1), pp.011014. 10.1117/1.OE.56.1.011014 . hal-01494304

\author{
HAL Id: hal-01494304 \\ https://hal.science/hal-01494304
}

Submitted on 29 May 2017

HAL is a multi-disciplinary open access archive for the deposit and dissemination of scientific research documents, whether they are published or not. The documents may come from teaching and research institutions in France or abroad, or from public or private research centers.
L'archive ouverte pluridisciplinaire HAL, est destinée au dépôt et à la diffusion de documents scientifiques de niveau recherche, publiés ou non, émanant des établissements d'enseignement et de recherche français ou étrangers, des laboratoires publics ou privés. 


\title{
Numerical study of laser ablation on aluminum for shock waves applications - Development of a suitable model by comparison with recent experiments
}

\author{
Simon Bardy, ${ }^{\text {a Bertrand Aubert, }}{ }^{\mathrm{b}}$ Laurent Berthe, ${ }^{\mathrm{c}}$ Patrick Combis, ${ }^{\text {a }}$ David Hébert, \\ Emilien Lescoute, ${ }^{a}$ Jean-Luc Rullier, ${ }^{b}$ Laurent Videau ${ }^{a}$ \\ ${ }^{a}$ CEA, DAM, DIF, F-91297 Arpajon, France \\ ${ }^{\mathrm{b}}$ CEA, DAM, CESTA, F-33114 Le Barp, France \\ ${ }^{\mathrm{c}}$ Laboratoire Procédés et Ingénierie en Mécanique et Matériaux, CNRS, Arts et Métiers ParisTech, 151 bd de \\ l'Hôpital, 75013 Paris, France
}

\begin{abstract}
In order to control laser-induced shock processes, two main points of interest must be fully understood: the laser-matter interaction generating a pressure loading from a given laser intensity profile and the propagation of induced shock waves within the target. This work aims to build a predictive model for laser shock-waves experiments with 2 grades of aluminum at low-middle intensities $\left(50-500 \mathrm{GW} / \mathrm{cm}^{2}\right)$ using the hydrodynamic Esther code. This 1D Lagrangian code manages both laser-matter interaction and shocks propagation. The numerical results are compared to recent experiments led on the Transportable Laser Shocks Generator (GCLT) facility. The results of this work motivate a discussion on the shock behavior dependence to elasto-plasticity and fracturation models. Numerical results of the rear surface velocity show a good agreement with the experimental results and it appears that the response of the material to the propagating shock is well predicted. The Esther code associated to this developed model can therefore be considered as a reliable predictive code for laser ablation and shockwaves experiments with pure Aluminum and 6061 Aluminum in the mentioned range of parameters. The Pressure-Intensity relationship generated by the Esther code is compared to previously established relationships.
\end{abstract}

Keywords: laser, shock, aluminum, hydrodynamics, elasto-plasticity, fracturation.

*Simon Bardy, E-mail: simon.bardy@cea.fr

\section{Introduction}

For the last decades, industrial applications of shocks generated by laser have arisen. They are based on lasers delivering from 1 to $100 \mathrm{~J}$ with pulse durations of several tens of ns. Focusing this type of laser beam on a target with a focal spot of some $\mathrm{mm}^{2}$ enables heating the matter from solid to plasma state by inverse Bremsstrahlung absorption [1]. Once created at the surface, the plasma tends to expand in all directions and an ablation pressure $\left(\mathrm{P}_{\mathrm{abl}}\right)$ of some GPa is created at the ablation front, in reaction to the ablated matter which is ejected in the normal direction to the front face. This ablation pressure is applied to the front face in some nanoseconds and generates therefore a shock wave in the material (Figure 1). Using a confining dielectric layer maximizes 
the shock pressure and duration in comparison to non-confined experiments which are traditionally led in vacuum atmosphere [2]; hence confined configurations are preferred for industrial applications. Monitoring the rear surface of thin targets with velocity measurement system is usually employed to characterize the shock amplitude on the rear surface.

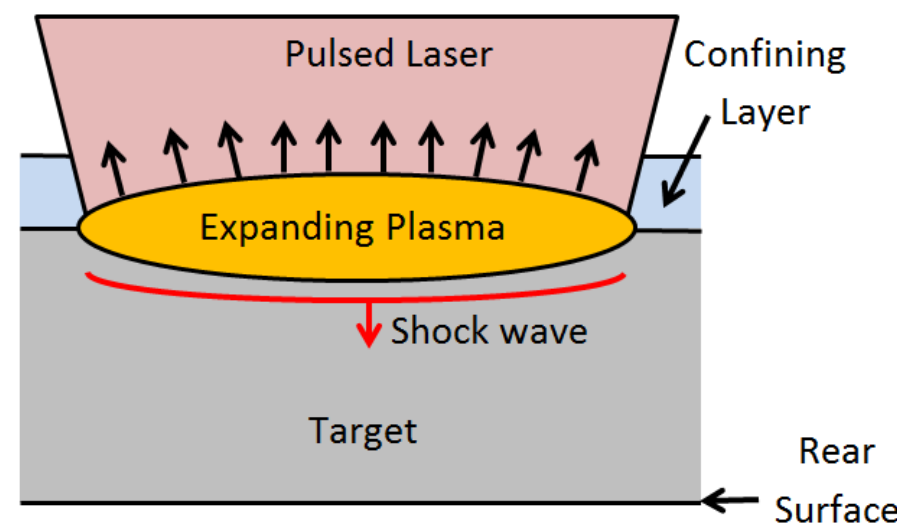

Fig. 1 Schematic view of the generation of a shock wave induced by laser

42 Mastering shockwaves within the material pave the way to industrial outcomes. In all cases of 43 application, the use of laser sources enables repeatability and eases the development of automatic 44 processes. Nowadays, the LASer Adhesion Test (LASAT) and the Laser Shock Peening (LSP), 45 identified as the two main laser shock processes, are well known in the industrial community.

46 The LASAT process aims to assess for the quality of interfaces within multi-layered structures 47 by steering shock waves generated by laser [3]. The LSP is seen as an alternative to classical shot 48 peening which uses high speed micro particles [4]. If the LASAT is expected to start its 49 development phase in various industrial sectors in the upcoming years, the LSP has already 50 proven its efficiency at industrial scale since the beginning of laser-driven shock understanding.

51 In addition, shocks induced by laser are seen as an alternative tool for characterizing solid 52 materials behavior under high speed loading up to $10^{7} \mathrm{~s}^{-1}$ without having to take the impactor 53 behavior into account [5] [6]. However, many challenges appear in the laser-matter interaction at 54 this moderate intensity range $\left(10-500 \mathrm{GW} / \mathrm{cm}^{2}\right)$ and even more at low intensities for confined 
configurations $\left(0.1-6 \mathrm{GW} / \mathrm{cm}^{2}\right)$. Some phenomena related to laser-matter interaction or mechanical behavior of materials, such as elasto-plasticity, may be negligible at higher regimes and have a determining influence in the laser shocks applications.

The development of a predictive numerical code for the applications mentioned above is the best way to design process parameters for related applications. Building this predictive code implies validation by experiments to identify key parameters for the development of new or existing models to be implemented within the considered code. This paper presents the first step of such approach which is the validation of Esther in a non-confined configuration. This is achieved coupling Esther code simulations and rear free velocity measurements of a reference material (Pure Aluminum) under laser shocks. Sensitivity of the code to material properties is also investigated with a different grade of aluminum (6061 Aluminum).

\section{Numerical tool}

Esther is a Lagrangian mono-dimensional code which manages both laser-matter interaction and shock propagation into the target [7] [8] [9] [10]. It solves the Helmholtz equation for the deposition of laser energy in the depth of skin and describes the evolution of material state from solid to plasma. It achieves hydrodynamic calculations on finite volumes using tabulated equations of state. Calculations include also radiative transfer and heat conduction models. A mechanical model (S-C-G [11]) has been added to reproduce elasto-plasticity of materials. A model for damaging and fracturation of materials (Johnson [12]) is also integrated to simulate spall experiments. This model describes the evolution of porosity in the material from an initial existing porosity to a maximal porosity that triggers spallation. This process is driven by stresses and enables the description of shock wave mechanics within the damaged material. Esther gives 
the opportunity to generate the temporal ablation pressure profile corresponding to a given temporal laser impulsion profile. This pressure profile can then be used in 2D-mechanical codes for studying shock propagation with bi-dimensional considerations.

\section{Experimental set-up}

We have performed experiments on the Transportable Laser Shock Generator (GCLT) of the CEA (Alternative Energies and Atomic Energy Commission) which delivers 1064-nm pulses up to $40 \mathrm{~J}$ with 3 to $100 \mathrm{~ns}$ durations. This flexibility in terms of pulse duration allows various studies of laser shock, either dedicated to laser-matter interaction or experimental evaluation of mechanical properties. The laser pulse temporal profile $(\mathrm{I}(\mathrm{t}))$ can be shaped in order to create an on-demand pulse shape such as Gaussian-like, Triangle or Top-Hat pulses. A vacuum facility enables direct ablation experiments with a control of the on-target spatial distribution of intensity by using phase plates. This configuration is available for spots diameter $\left(\mathrm{d}_{\mathrm{foc}}\right)$ from $0.25 \mathrm{~mm}$ to $4.4 \mathrm{~mm}$. A 532-nm VISAR system [13] allows rear surface velocity measurement on the target rear surface, as shown on Figure 2.

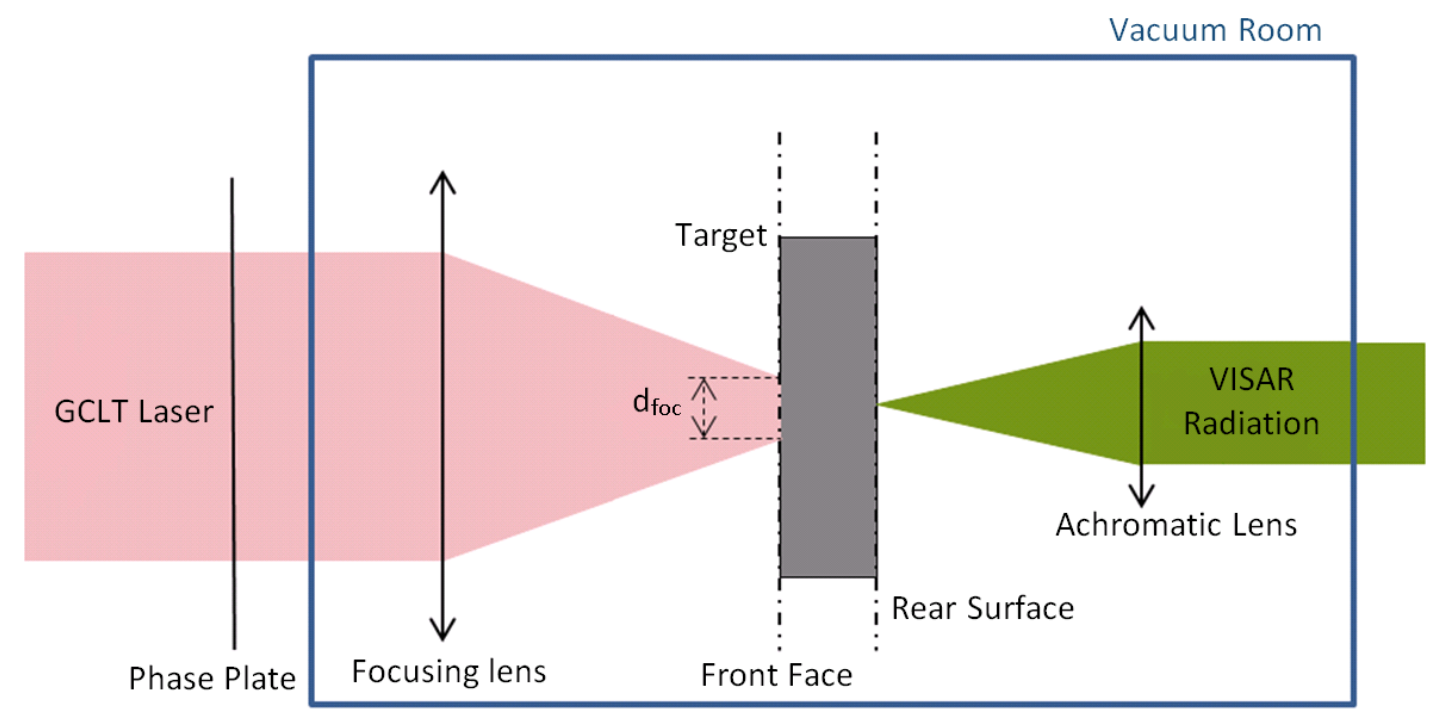

Fig. 2 Schematic view of the experimental set-up used on GCLT 
Experiments have been performed on two different grades of aluminum: a pure laminated Aluminum 99.999\% and a 6061 Aluminum alloy. Material thicknesses (t) are included in a range of $250 \mu \mathrm{m}$ to $335 \mu \mathrm{m}$ and pulses duration $(\tau)$ varies from $5 \mathrm{~ns}$ to $10 \mathrm{~ns}$. Maximal intensities (I) vary from $50 \mathrm{GW} / \mathrm{cm}^{2}$ to $500 \mathrm{GW} / \mathrm{cm}^{2}$ in Top-Hat configuration, which gives insights of very different configurations. For each shot of the mentioned campaign, the temporal intensity profile and the rear surface velocity profile are extracted.

\section{Development of models for materials}

Figure 3 and 4 give a comparison of experimental and numerical rear free surface velocities and corresponding pressure space-time diagrams extracted from calculation. Intensities are in the range of $170-180 \mathrm{GW} / \mathrm{cm} 2$ for $10 \mathrm{~ns}$ pulse duration and these experiments were led on pure Aluminum and Aluminum 6061 samples respectively. The sensitivity of shock to an intensity variation of $+/-10 \%$ is also calculated for the numerical signals. Simulations with and without Johnson damage model have been performed. The Johnson model used for this study reproduces material damaging by retroaction on the equation of state and mechanical model. If a certain

threshold of damaging is exceeded, fracturation occurs. In both cases described previously, modelling the rear surface velocity with and without fracturation model eases the interpretation of material damaging and eventual fracturation. 
a)

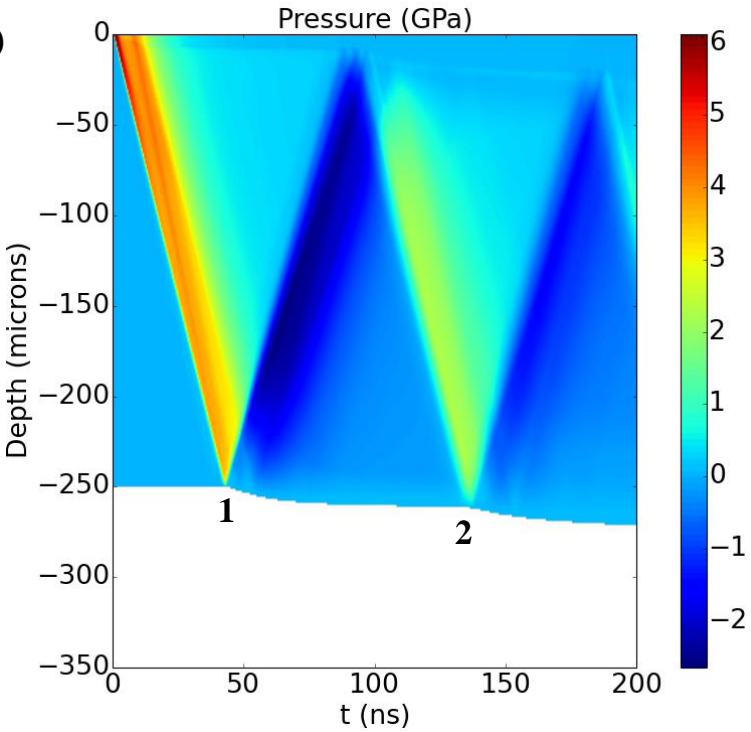

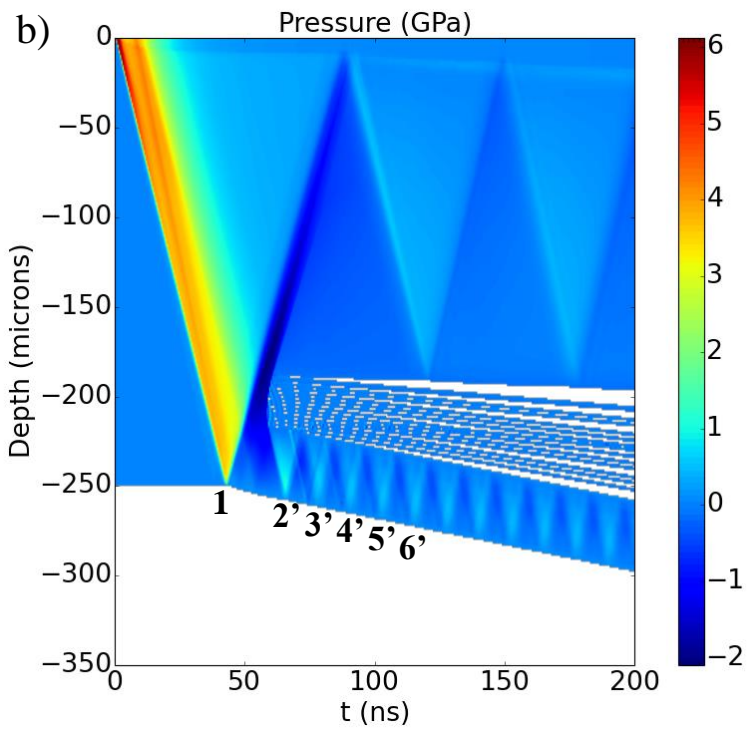

c)

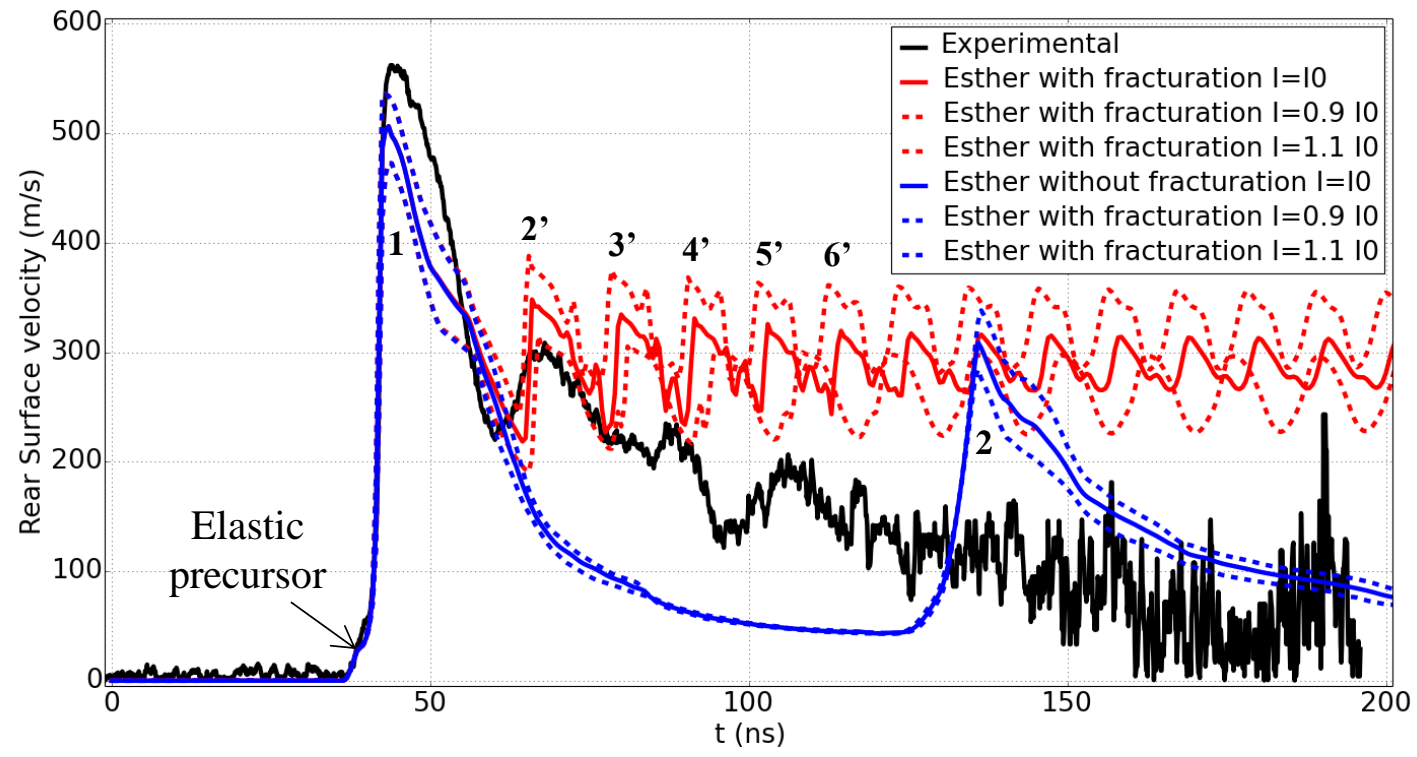

Fig. 3 Space-time diagram without fracturation model (a), with fracturation model (b) and rear surface velocity profile (c) obtained by simulation (+/- $10 \%$ on E) with fracturation (red), without fracturation (blue), and compared to the experimental signal - Pure Aluminum $-\mathrm{E}=18.3 \mathrm{~J}-\mathrm{t}=250 \mu \mathrm{m}-\tau=10 \mathrm{~ns}-\mathrm{dfoc}=1 \mathrm{~mm}\left(\mathrm{I}=170 \mathrm{GW} / \mathrm{cm}^{2}\right)$ Typically, rear free surface velocity is characterized by successive oscillations corresponding to shock waves going back and forth within the target [14]. The period of these oscillations is given by equation (1). 


$$
\text { Period }=\frac{2 . \text { Thickness }}{\text { Shock Wave Velocity }}
$$

In the cases without fracturation model described here (Figure 3 a), Figure 4 a) and blue curves on Figure 3 c) and Figure 4 c)), the period of oscillations linked to shockwaves going back and forth within the target thickness is about 90 ns. It is typical of shockwaves travelling through 250 $\mu$ m-thick aluminum targets. Maxima 1 and 2 correspond to shocks coming out onto the target free surface and minima are related to the end of unloading of the free surface by release waves. If damage occurs within the target (Figure $4 \mathrm{~b}$ ) and red curves on Figure $4 \mathrm{c}$ )), the maximum after the first peak $\left(\mathbf{2}^{\prime}-180 \mathrm{~m} / \mathrm{s}\right)$ is attenuated in comparison to the case without fracturation $(\mathbf{2}-$ $310 \mathrm{~m} / \mathrm{s}$ ). This may be due to energy dissipation involved in the damaging process. The increase of porosity simulated by the fracturation model can be seen as spending energy into the creation of many new surfaces. If fracturation occurs (Figure 3 b) and red curves on Figure 3 c)), there is then apparition of two new free surfaces by spallation. In this case, the resulting rear surface velocity maxima $\left(2^{\prime}, 3^{\prime}, 4^{\prime}, 5^{\prime}, 6^{\prime}\right)$ refers to back and forth of shock and release waves within the spall, hence a higher frequency of oscillations (Period $\approx 20 \mathrm{~ns}$ ). Simulation results prove here the existence of damaging of Aluminum 6061 and 1-D spallation of the pure Aluminum sample. 

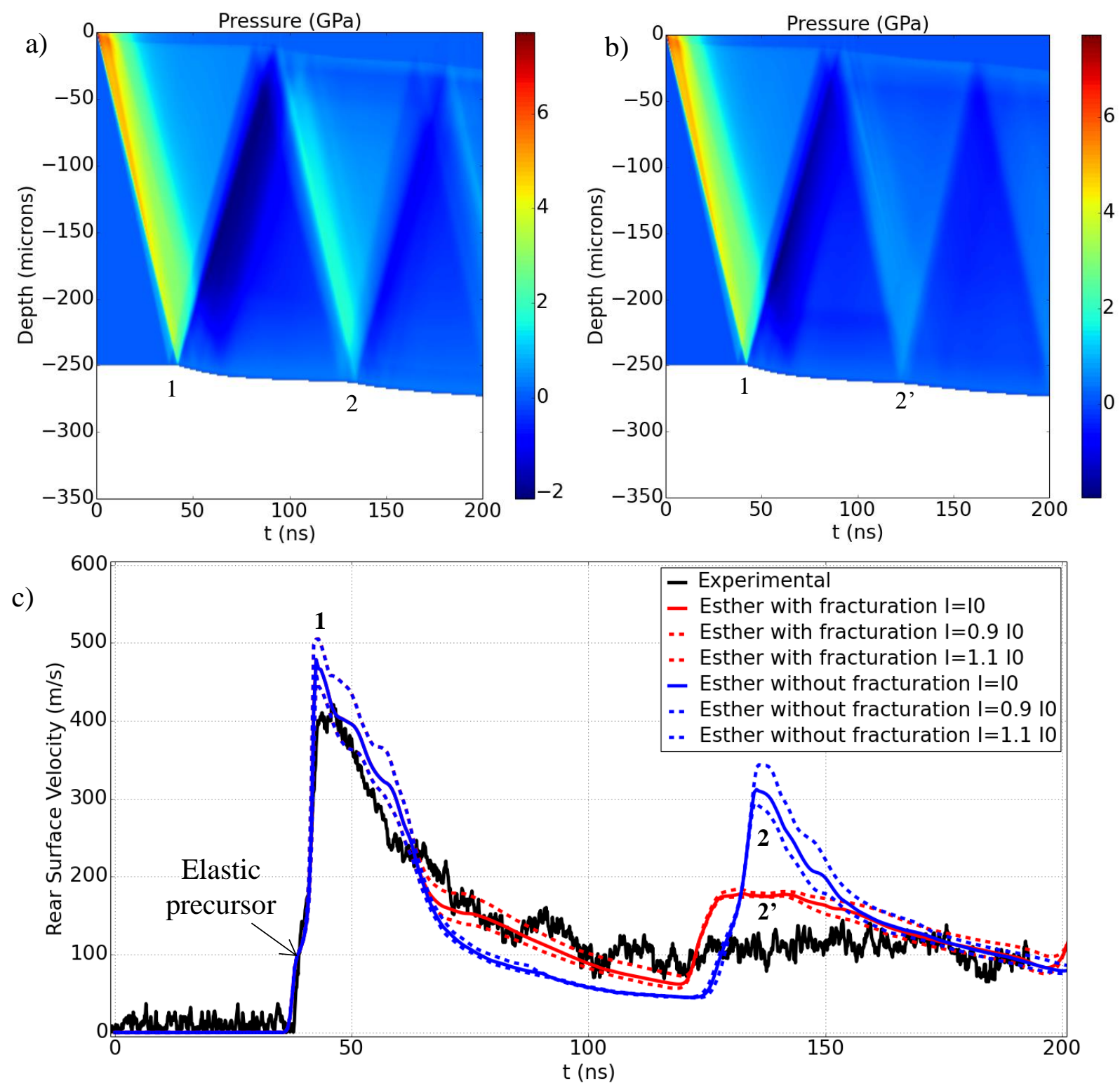

Fig. 4 Space-time diagram without fracturation model (a), with fracturation model (b) and rear surface velocity profile (c) obtained by simulation (+/- $10 \%$ on E) with fracturation (red), without fracturation (blue), and compared to the experimental signal - Aluminum $6061-\mathrm{E}=20.3 \mathrm{~J}-\mathrm{t}=250 \mu \mathrm{m}-\tau=10 \mathrm{~ns}-\mathrm{dfoc}=1 \mathrm{~mm}\left(\mathrm{I}=180 \mathrm{GW} / \mathrm{cm}^{2}\right)$

At first glance, experimental results show very different behavior of both materials, regarding key zones of the rear surface velocity profile, i.e. elastic precursor, maximal velocity and unloading of the rear surface. This was confirmed by Vickers micro-hardness measurements led 
on both materials. A factor 3 exists between both materials since Pure Aluminum and 6061 Aluminum exhibit a hardness of 40 and 117 respectively (Table 1). This implies a difference of the same order of magnitude in terms of strength and a similar difference of yield strength. This static mechanical information is correlated to the elastic precursors visible on the rear surface velocity profiles, which show also a difference factor of the same order of magnitude $(30 \mathrm{~m} / \mathrm{s}$ for Pure Aluminum vs. 100m/s for 6061 Aluminum).

Table 1 Results of Vickers micro-hardness measurements led on samples

\begin{tabular}{lll}
\cline { 2 - 3 } & \multicolumn{2}{c}{ HV 50g } \\
\cline { 2 - 3 } & Pure Aluminum & $\mathbf{6 0 6 1}$ Aluminum \\
\hline Average Value & $\mathbf{4 0}$ & $\mathbf{1 1 7}$ \\
Standard Deviation & 2.0 & 7.9 \\
Coefficient of Variation & $4.9 \%$ & $6.8 \%$ \\
\hline
\end{tabular}

Simulations realized with Esther show very good accordance with the experimental curves. Elastic precursors, related to the elasto-plasticity behavior of materials, are correctly defined. The maximal velocity peak, impacted by both laser-matter interaction and mechanics is also well reproduced considering the uncertainty on incident intensity (+/- 10\%) and its influence on the rear surface velocity. Taking into account a good definition of elasto-plasticity in simulations and the accordance on the maximal rear surface velocity, the laser-matter interaction is then well defined by Esther. The cut-off point on pure Aluminum and the unloading phase of the Aluminum 6061 are also correctly reproduced in simulations, even if perfectible. These observations count for a good modelling of materials damaging occurring for both materials. Esther reveals here its ability to reproduce laser shock experiments on materials with very different mechanical behaviors.

Same laser parameters have been used for generating a shock in a thicker sample. Both experimental and simulation results are described on Figure 5. 


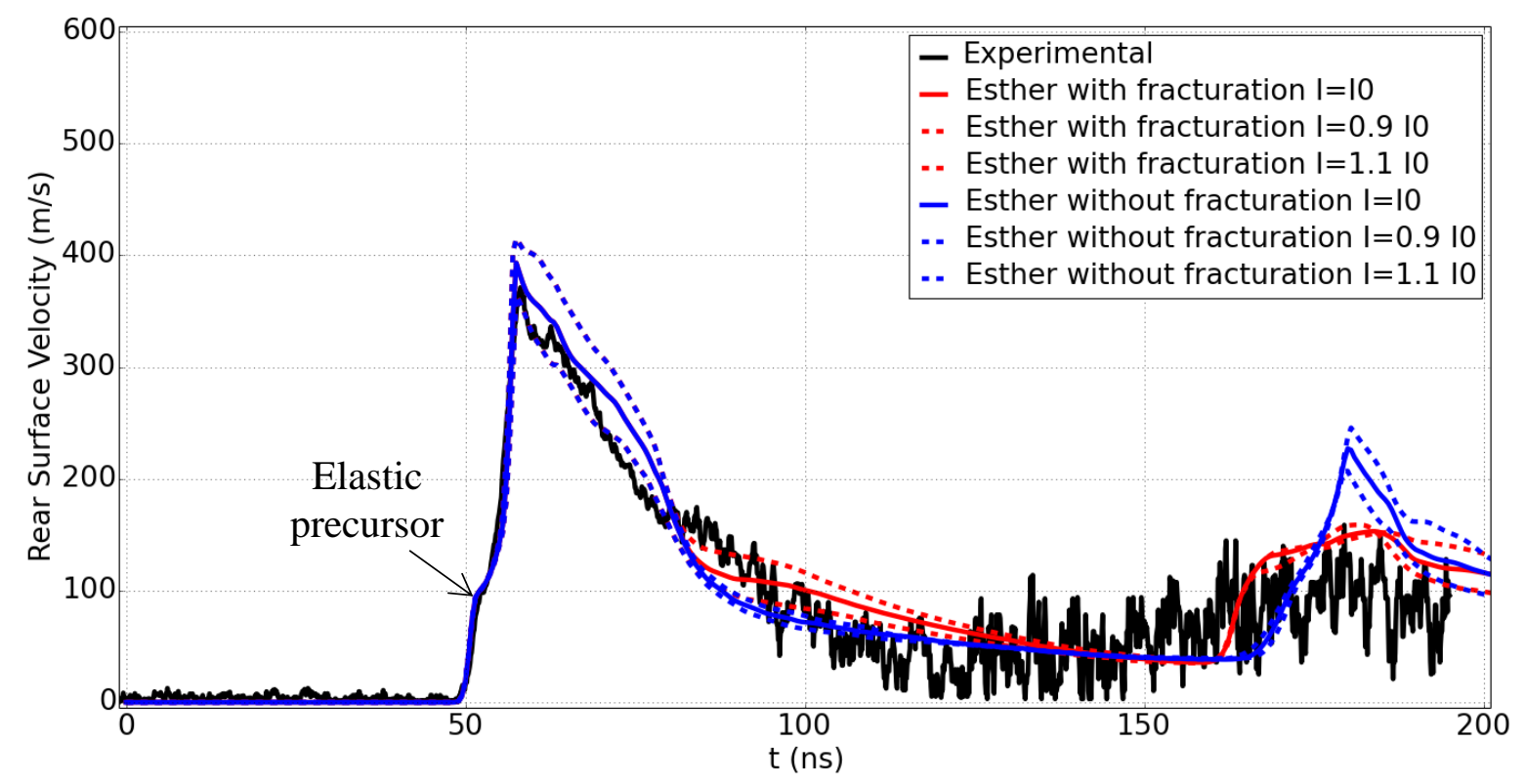

Fig. 5 Rear surface velocity profile obtained by simulation (+/- 10\% on E) with fracturation (red) and without fracturation (blue) and compared to the experimental signal - Aluminum $6061-\mathrm{E}=18.2 \mathrm{~J}-\mathrm{t}=335 \mu \mathrm{m}-\tau=10 \mathrm{~ns}-$

$$
\text { dfoc }=1 \mathrm{~mm}\left(\mathrm{I}=170 \mathrm{GW} / \mathrm{cm}^{2}\right)
$$

Comparing Figure 4 and 5 allows having an insight of the effects of thickness on the behavior of Aluminum 6061 under identical laser shock conditions [15]. Both configurations generate quite similar profiles. Maximal rear surface velocity is, as expected, lower for the $335 \mu \mathrm{m}$-thick sample $(371 \mathrm{~m} / \mathrm{s}$ vs. $420 \mathrm{~m} / \mathrm{s})$. The elastic precursor is easier to identify on the $335 \mu \mathrm{m}$-thick sample due to a longer propagation within the target enabling larger arrival time difference between elastic precursor and plastic shock. The simulated elastic precursor fits perfectly the experimental one and confirms here the reliability of the mechanical model associated to Esther for such an experiment. The comparison of numerical signals generated with and without fracturation model with the experimental curve obviously demonstrates that this target was damaged, even if not clearly fractured. 
Laser shock experiments with lower intensity have been led in order to observe the reliability of Esther at very low intensity and quasi elasto-plasticity regime. Results are exposed on Figure 6.

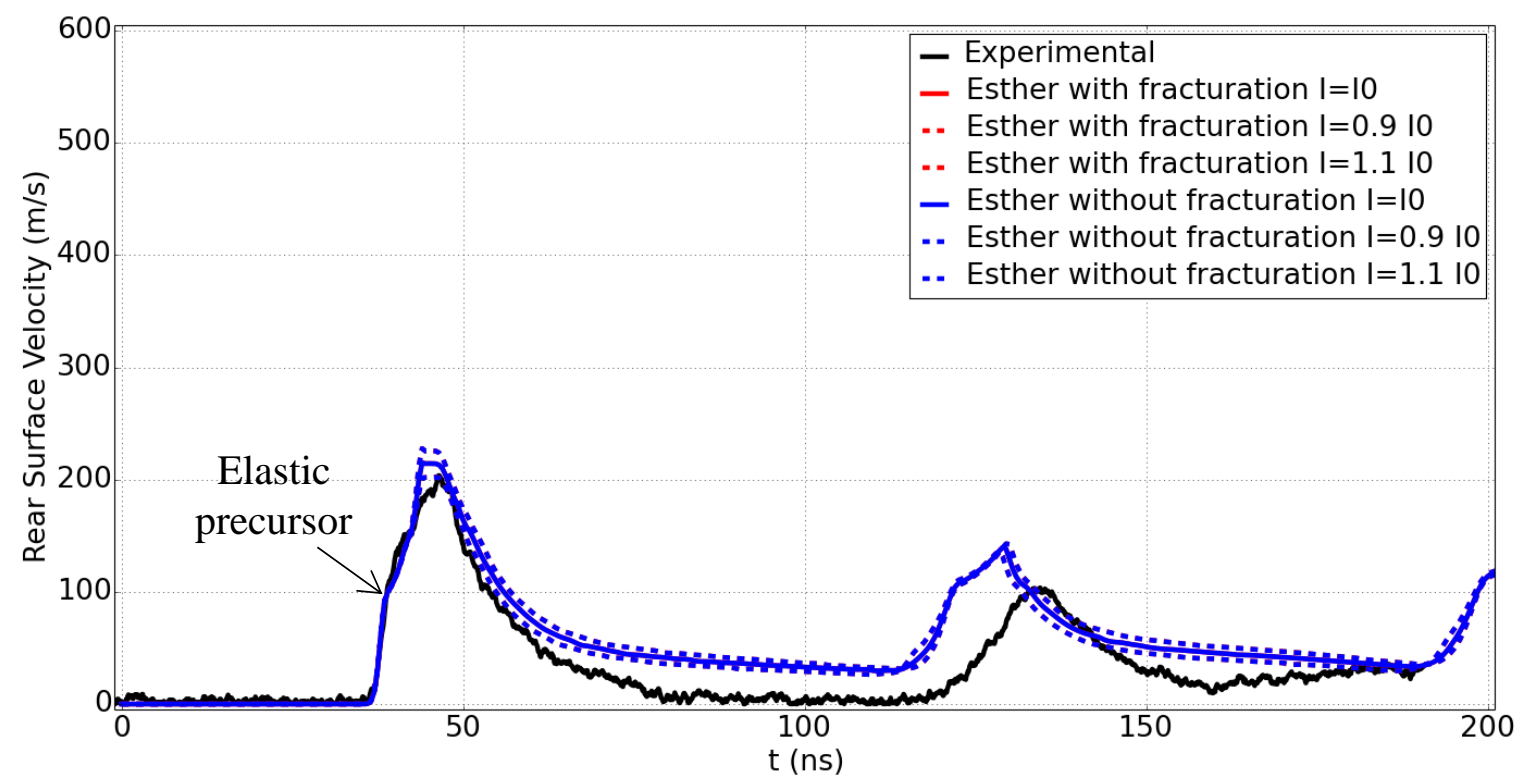

Fig. 6 Rear Surface velocity profile obtained by simulation (+/- 10\% on E) with fracturation (red) and without fracturation (blue) and compared to the experimental signal - Aluminum $6061-\mathrm{E}=6.1 \mathrm{~J}-\mathrm{t}=250 \mu \mathrm{m}-\tau=10 \mathrm{~ns}-$ dfoc $=1 \mathrm{~mm}\left(\mathrm{I}=50 \mathrm{GW} / \mathrm{cm}^{2}\right)$

Figure 4 and 6 refer to the same experimental conditions, except about 3 times less induced intensity on the results of Figure 6. In this configuration, the maximal rear surface velocity is slightly higher than the elastic precursor $(200 \mathrm{~m} / \mathrm{s}$ and $100 \mathrm{~m} / \mathrm{s}$ for the beginning of elastic precursor). Simulations curves representing $+/-10 \%$ of uncertainty on intensity are very close to each other $(20 \mathrm{~m} / \mathrm{s}$ of difference on the peak value). They reveal the small dependence of rear surface velocity to intensity in this regime. The resulting behavior must then be largely influenced by the mechanical model of the material and poorly affected by laser-matter interaction. This must imply that a large part of induced energy is converted into elastic strain energy and hardening of the material. A very small part is dedicated to hydrodynamic plastic 
shock. The elastic precursor is accurately simulated by Esther, confirming the reliability of the mechanical model. The first peak is reasonably well reproduced but the unloading phase could be better fitted with a slightly lower maximal rear surface velocity. After $100 \mathrm{~ns}$, bi-dimensional effects can be considered to significantly impact the rear surface velocity. After this time, the large discrepancy between simulation and experimental results can be attributed, for a nonnegligible part, to $2 \mathrm{D}$ effects [16].

\section{Impact of modulations in I(t)}

The experimental I(t) profiles shows modulations intrinsic to the GCLT laser source (Figure 7). These modulations are about 10-15\% around the intensity of a perfect Top-Hat pulse which has the same experimental fluence $\left(\mathrm{F}_{\mathrm{eq}}\right)$. As shown on Figure 8, these modulations are reported in the ablation pressure profile $\left(\mathrm{P}_{\mathrm{abl}}(\mathrm{t})\right)$, numerically determined with Esther. While the shock wave propagates within the target thickness, these modulations are attenuated. Beyond $200 \mu \mathrm{m}$ of propagation, the form of the pressure profile $(\mathrm{P}(\mathrm{t}))$ generated with the experimental $\mathrm{I}(\mathrm{t})$ corresponds to the theoretical Top-hat one. The first peak of the experimental profile is higher than the maximal intensity of the theoretical Top-Hat which explains a higher maximum in $\mathrm{P}_{\mathrm{abl}}(\mathrm{t})$. However, the here above-mentioned modulations are responsible of multiple release waves within the pressure profile. They increase the attenuation of the pressure peak along the propagation within the thickness. At $250 \mu \mathrm{m}$ of propagation, both experimental and theoretical Top-Hat profiles have the same maximal pressure value. Beyond this value, the experimental profile has a lower maximal, generating a maximal rear surface velocity $(\mathrm{v}(\mathrm{t}))$ slightly smaller than the one obtained with a theoretical Top-Hat (Figure 9). 


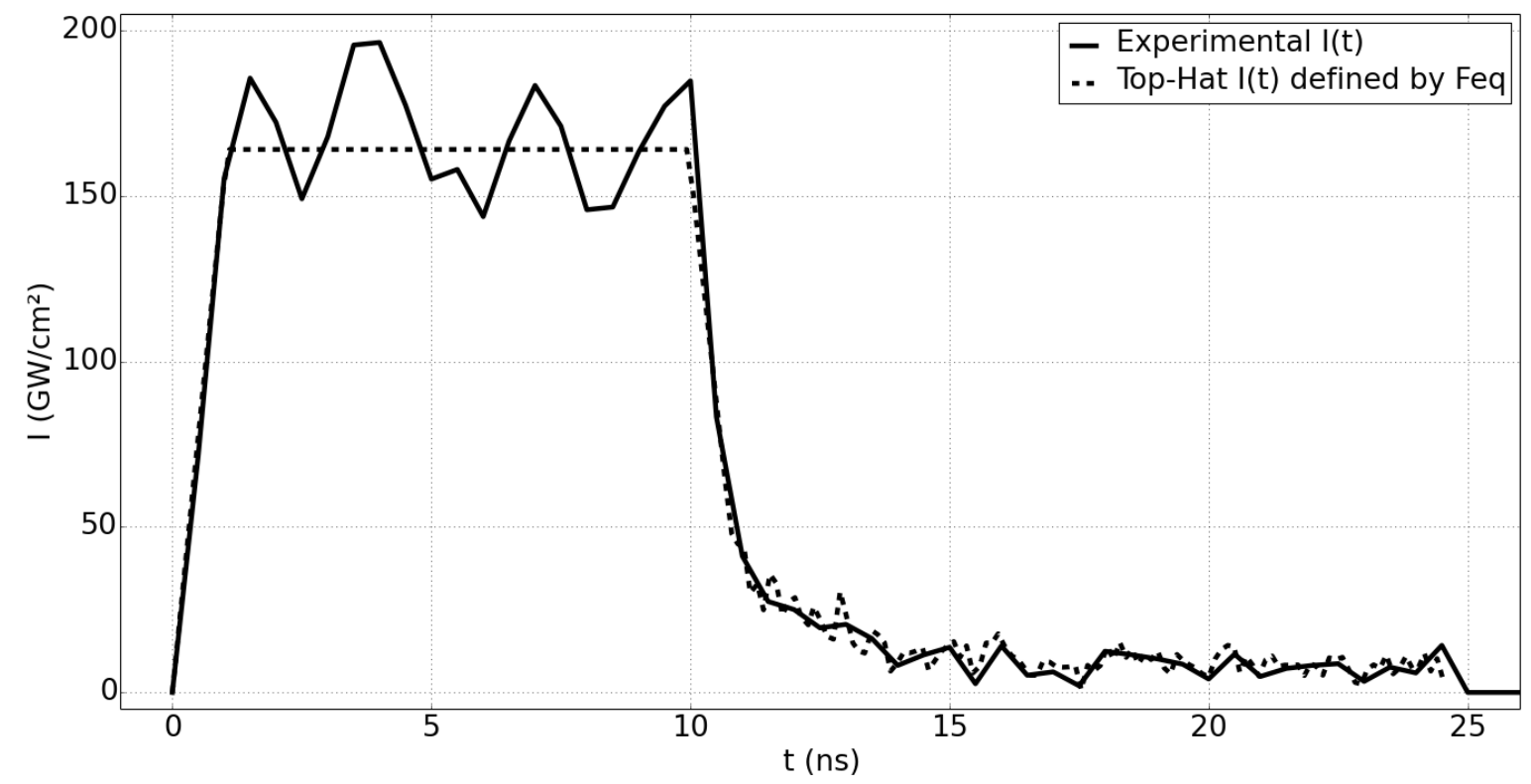

Fig. 7 I(t) for a 10-ns GCLT Top-Hat (full line), and 10-ns numerical Top-Hats defined with a fluence equal to the measured experimental fluence (dotted line)

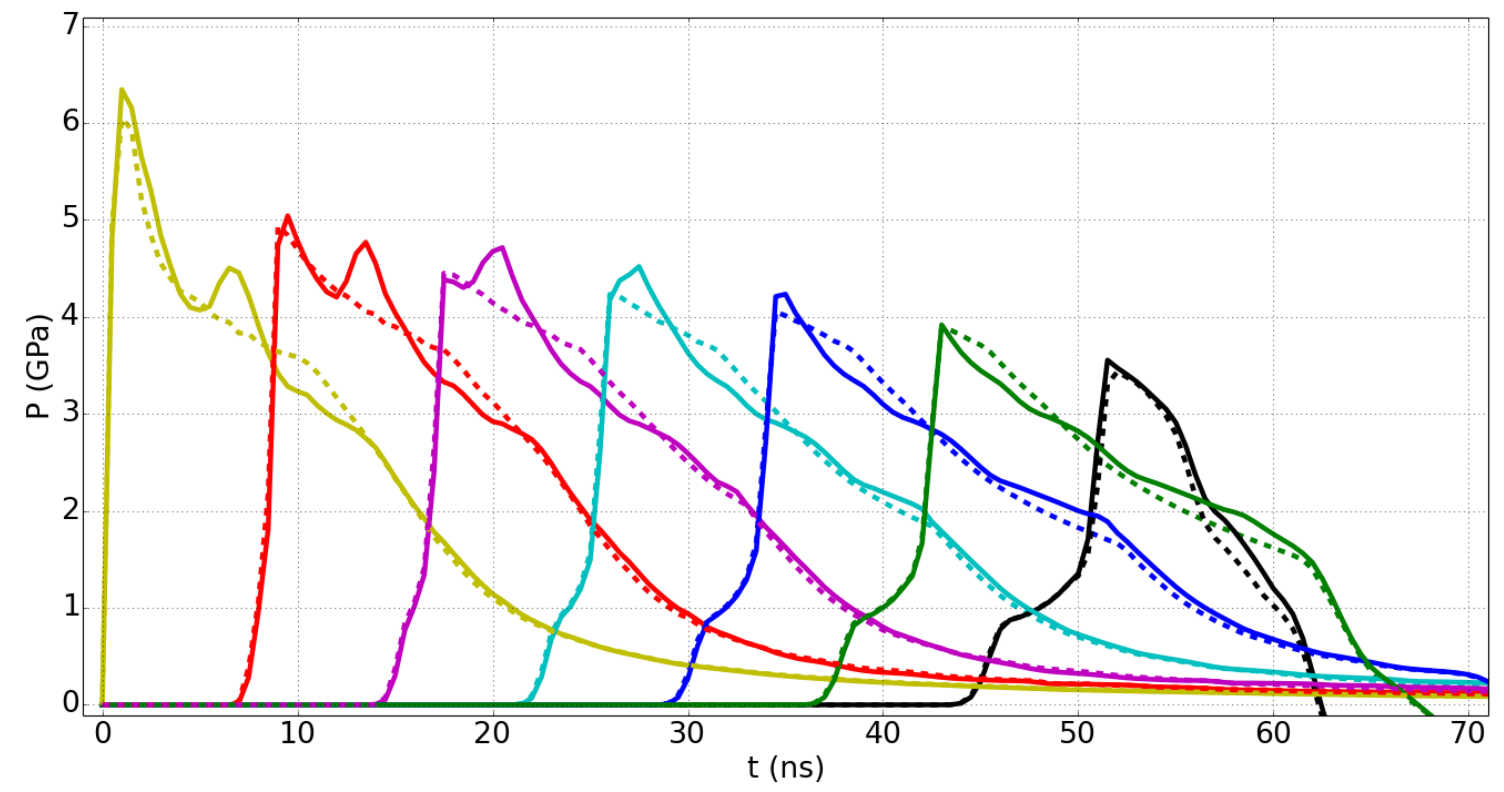

Fig. 8 Pabl(t) (yellow) and P(t) at $50 \mu \mathrm{m}$ (red), $100 \mu \mathrm{m}$ (magenta), $150 \mu \mathrm{m}$ (pale blue), $200 \mu \mathrm{m}$ (dark blue) and 250 $\mu \mathrm{m}$ (green) of propagation for a 10-ns GCLT Top-Hat (full lines) and 10-ns numerical $\mathrm{F}_{\mathrm{eq}}$ Top-Hats (dotted line) 


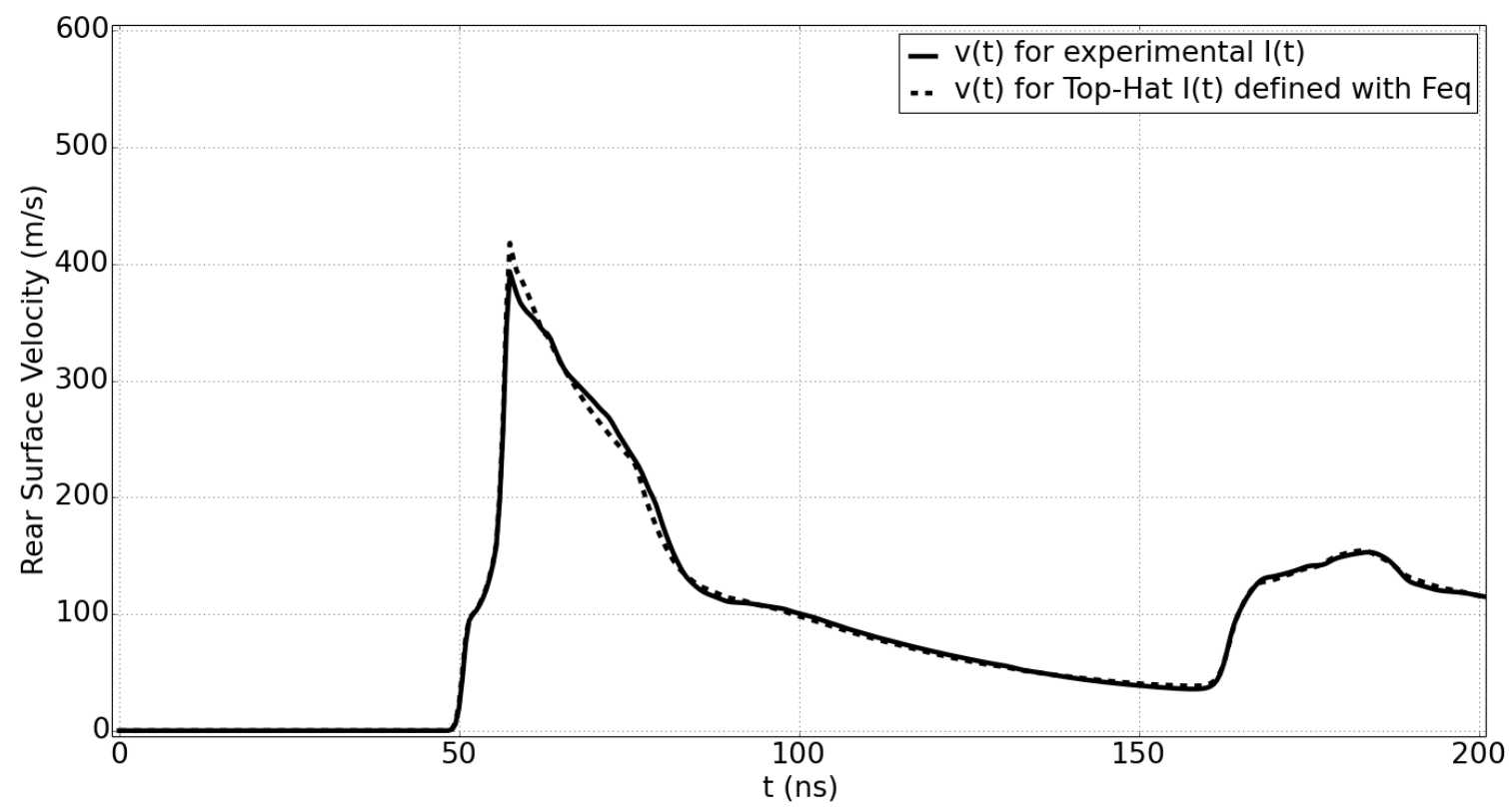

Fig. 9 v(t) for a 10-ns GCLT Top-Hat (full line) and a 10-ns numerical Top-Hat defined with a $\mathrm{F}_{\text {eq }}$ (dotted line) This numerical study highlights the diminution of modulations in the temporal loading profile with the propagation in the material. It shows that these perturbations have no significant impact on the shape of the rear face velocity peak and a very limited impact on the maximal rear face velocity. Using a perfect Top-Hat impulsion for numerical predictions in the frame of future experimental campaigns should give a good approach of what is expected with real profiles.

\section{Validating laser-matter interaction model with Esther}

As mentioned before, Esther simulates the laser-matter interaction to generate an ablation pressure used as mechanical solicitation for modelling the behavior of material under shock loading. In order to validate the ability of Esther to generate adequate ablation pressure, P-I points obtained with Esther must be compared to a well-known $\mathrm{P}=\mathrm{f}(\mathrm{I})$ law such as the one developed by Phipps from the works of Caruso [17], [18], Nemchinov [19] and Kidder [20]:

$$
P a b l=A \cdot I^{3 / 4} \cdot \lambda^{-1 / 4} \cdot \tau^{-1 / 8}
$$


It has been identified by Phipps as the best law for representing experiments [21]. In this study A was chosen as equal to 1 .

$\mathrm{P}_{\mathrm{abl}}(\mathrm{t})$ are obtained with Esther, using the model used for fitting experiments results with simulations (IV). This numerical study is achieved with a range of intensities from 50 to $500 \mathrm{GW} / \mathrm{cm}^{2}$ for 5-ns, 10-ns and 50-ns for Top-Hat and Gaussian pulses. The maximum value of $P_{a b l}(t)$ is extracted and plotted versus the maximum value of $I(t)$. Results are described on Figure 10.

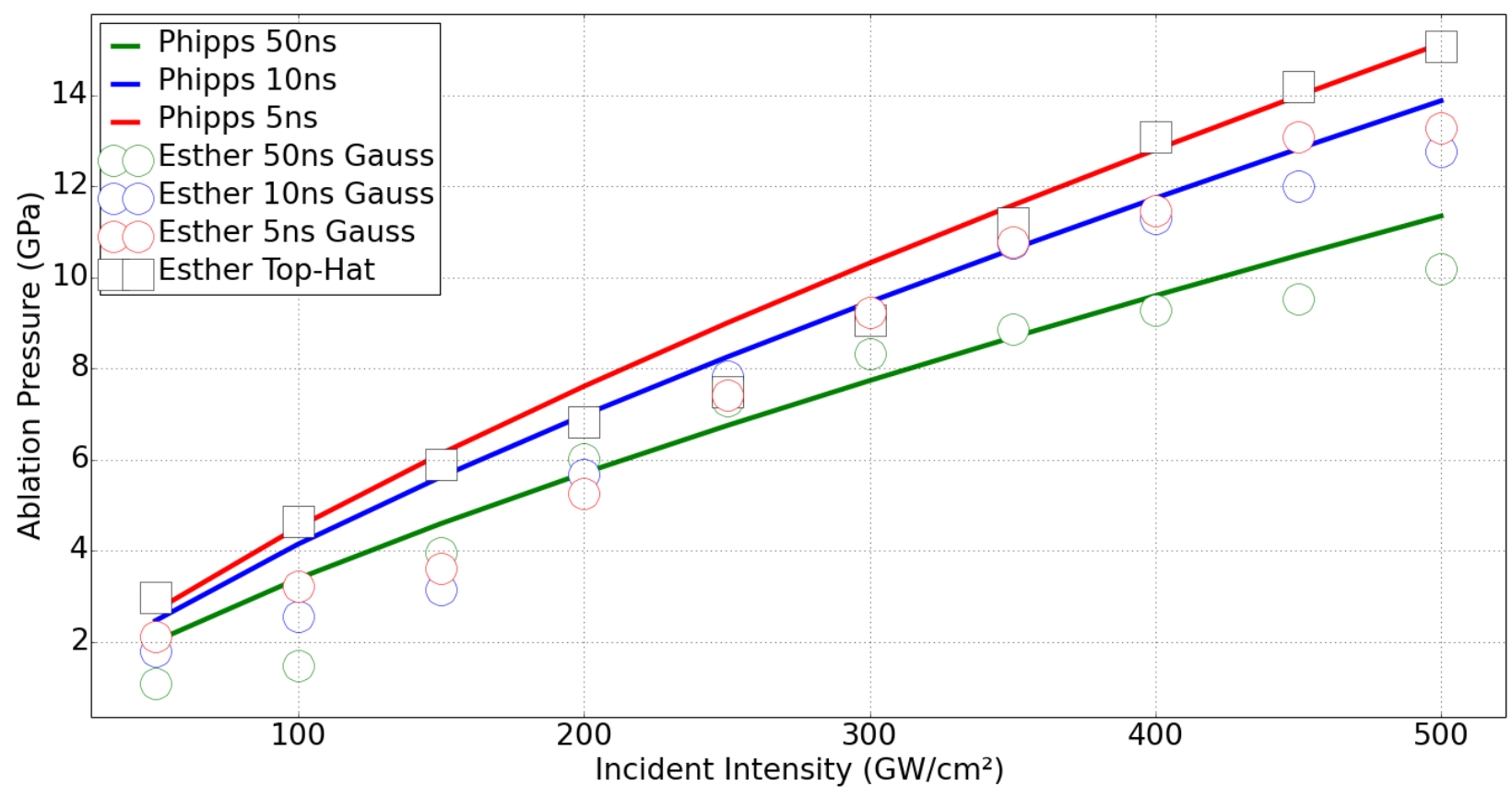

Fig. $10 \mathrm{P}=\mathrm{f}(\mathrm{I})$ with $\mathrm{P}(\mathrm{t})$ defined with Esther and from the equation (2)

For Gaussian pulses obtained with Esther, an increase in $\mathrm{P}$ with a decrease of pulse duration is to be noticed. This is corroborated by Phipps' law. The overall trend of all points obtained with Esther for Gaussian profiles show the same progression of P than Phipps law. Despite some fluctuations, this agreement is good, especially for rather high intensities $\left(>250 \mathrm{GW} / \mathrm{cm}^{2}\right)$. P-I points with Top-Hat impulsions obtained with Esther are very close to the one obtained with Phipps law for 5-ns impulsions. For these Top-Hat pulse configurations, maximal values of 
$P_{a b l}(t)$ seem to not be influenced by the pulse duration $(\tau)$ since simulations realized with Esther generates exactly the same maximum in ablation pressure, whatever $\tau$. In the considered regimes, $\tau$ seems to have an influence on the loading duration but the maximum value is generated by the very first ns of interaction. Hence, at equal intensity, a Top-Hat laser impulsion generates equal maximum of $\mathrm{P}_{\mathrm{abl}}$.

\section{Conclusion}

The use of Esther for reproducing experiments has been demonstrated. The results presented here show a coherent laser-matter interaction and accurate simulation of mechanics, shock behavior, damaging and fracturation of materials. In the considered configurations, this code demonstrates its ability and can therefore be used for predicting and designing future laser experiments in nonconfined configurations. Future work has to be done in order to develop Esther for materials such as polymers, composites and alloys under laser shock in confined configuration.

\section{References}

1. P. Mora, "Theoretical model of absorption of laser light by a plasma," Physics of Fluids, 25, $1051(1982)$

2. N.C. Anderholm, "Laser-generated stress waves," Applied Physics Letters, 16, 113 (1970)

3. L. Berthe et al., "State-of-the-art laser adhesion test (LASAT)," Nondestructive Testing and Evaluation, 26 (3-4), 303-317 (2011)

4. R. Fabbro et al., "Physics and applications of laser-shock processing," Journal of Laser Applications, 10 (6), 265-279 (1998)

5. G. Seisson et al., "Dynamic fragmentation of graphite under laser-driven shocks: Identification of four damage regimes," International Journal of Impact Engineering, 91, 66-79 (2016) 
6. D. Laporte, "Analysis of the response of bonded assemblies under shock wave loading Experiments and modelling,” PhD. Manuscript (2011)

7. J. P. Colombier et al., "Hydrodynamic simulations of metal ablation by femtosecond laser irradiation," Physical Review B, 71, 165406 (2005)

8. P. M. Leguay et al., "Ultrafast Short-Range Disordering of Femtosecond-Laser-Heated Warm Dense Aluminum," Physical Review Letters, 111, 245004 (2013)

9. S. Laffite et al., "Velocity Interferometer blanking due to preheating in a double pulse planar experiment," Physics of Plasma, 21, 082705 (2014)

10. G. Seisson et al., "Dynamic cratering of graphite: experimental results and simulations," International Journal of Impact Engineering, 63 (2014)

11. D. J. Steinberg et al., “A constitutive model for metals applicable at high strain rate," Journal of Applied Physics, 51, 1498 (1980)

12. J. N. Johnson, "Dynamic fracture and spallation in ductile solids," Journal of Applied Physics, 52, $2812(1981)$

13. L. M. Barker et al., "Laser interferometer for measuring high velocities of any reflecting surface," Journal of Applied Physics, 43, 4669 (1972)

14. L. Tollier et al., "Study of the laser-driven spallation process by the velocity interferometer system for any reflector interferometry technique. I. Laser-shock characterization," Journal of Applied Physics, 83, 1224 (1998)

15. F. Cottet et al., "Spallation studies in aluminum targets using shock waves induced by laser irradiation at various pulse durations," Journal of Applied physics, 66 (9), 4067-4073 (1989)

16. M. Boustie et al., "Study of damage phenomena induced by edge effects into materials under laser driven shocks," Journal of Physics D: Applied Physics, 40, 7103-7108 (2007)

17. A. Caruso et al., "Ionization and heating of solid material by means of a laser pulse," Nuovo Cimento, 45, 176 (1966) 
18. A. Caruso et al., "Some properties of the plasmas produced by irradiating light solids by laser pulses”, Plasma Physics, 10, 867 (1968)

19. I. V. Nemchinov, "Steady-state motion of radiation-heated vapors of a material in the presence of lateral spreading flow," Journal of Applied Math. And Mech., 31, 320 (1967)

20. R. E. Kidder, "Application of lasers to the production of high-temperature and high-pressure plasma," Nucl. Fusion, 8, 3 (1968).

21. C.R. Phipps et al., "Impulse coupling to targets in vacuum by $\mathrm{KrF}, \mathrm{HF}$, and $\mathrm{CO} 2$ single-pulse lasers," Journal of Applied Physics, 64, 1083 (1988)

\section{Biographies}

Simon BARDY received a Master degree from the European School of Material Sciences and Engineering in 2014.

After having worked 1 year in a mechanical testing department of a major producer of civil aircrafts, he is currently $\mathrm{PhD}$ student in daily collaboration with Dr. Laurent VIDEAU at the Alternative Energies and Atomic Energy Commission (CEA, DAM, DIF), under the supervision of Dr. Laurent BERTHE (PIMM-ENSAM ParisTech). His works aim at developing the LASer Adherence Test (LASAT).

Other biographies are not available. 


\section{$\underline{\text { Table Caption List }}$}

Table 1 Results of Vickers micro-hardness measurements led on samples

\section{Figure Caption List}

Fig. 1 Schematic view of the generation of a shock wave induced by laser

Fig. 2 Schematic view of the experimental set-up used on GCLT

Fig. 3 Space-time diagram without fracturation model (a), with fracturation model (b) and rear surface velocity profile (c) obtained by simulation (+/- 10\% on E) with fracturation (red), without fracturation (blue), and compared to the experimental signal - Pure Aluminum - E=18.3 $\mathrm{J}-\mathrm{t}=250 \mu \mathrm{m}-\tau=10 \mathrm{~ns}-\mathrm{dfoc}=1 \mathrm{~mm}\left(\mathrm{I}=170 \mathrm{GW} / \mathrm{cm}^{2}\right)$.

Fig. 4 Space-time diagram without fracturation model (a), with fracturation model (b) and rear surface velocity profile (c) obtained by simulation (+/- 10\% on E) with fracturation (red), without fracturation (blue), and compared to the experimental signal - Aluminum 6061 - E=20.3 $\mathrm{J}-\mathrm{t}=250 \mu \mathrm{m}-\tau=10 \mathrm{~ns}-\mathrm{dfoc}=1 \mathrm{~mm}\left(\mathrm{I}=180 \mathrm{GW} / \mathrm{cm}^{2}\right)$.

Fig. 5 Rear surface velocity profile obtained by simulation (+/- 10\% on E) with fracturation (red), without fracturation (blue), and compared to the experimental signal - Aluminum 6061 $\mathrm{E}=18.2 \mathrm{~J}-\mathrm{t}=335 \mu \mathrm{m}-\tau=10 \mathrm{~ns}-\mathrm{dfoc}=1 \mathrm{~mm}\left(\mathrm{I}=170 \mathrm{GW} / \mathrm{cm}^{2}\right)$

Fig. 6 Rear surface velocity profile obtained by simulation $(+/-10 \%$ on E) with fracturation (red), without fracturation (blue), and compared to the experimental signal - Aluminum 6061 $\mathrm{E}=6.1 \mathrm{~J}-\mathrm{t}=250 \mu \mathrm{m}-\tau=10 \mathrm{~ns}-\mathrm{dfoc}=1 \mathrm{~mm}\left(\mathrm{I}=50 \mathrm{GW} / \mathrm{cm}^{2}\right)$

Fig. 7 I(t) for a 10-ns GCLT Top-Hat (full line), and 10-ns numerical Top-Hats defined with a fluence equal to the measured experimental fluence (dotted line) 
Fig. $8 \mathrm{P}_{\mathrm{abl}}(\mathrm{t})($ yellow) and $\mathrm{P}(\mathrm{t})$ at $50 \mu \mathrm{m}$ (red), $100 \mu \mathrm{m}$ (magenta), $150 \mu \mathrm{m}$ (pale blue), $200 \mu \mathrm{m}$ (dark blue) and $250 \mu \mathrm{m}$ (green) of propagation for a 10-ns GCLT Top-Hat (full lines) and 10-ns numerical $\mathrm{F}_{\text {eq }}$ Top-Hats (dotted line)

Fig. 9 v(t) for a 10-ns GCLT Top-Hat (full line) and a 10-ns numerical Top-Hat defined with a $\mathrm{F}_{\mathrm{eq}}($ dotted line $)$

Fig. $10 \mathrm{P}=\mathrm{f}(\mathrm{I})$ with $\mathrm{P}(\mathrm{t})$ defined with Esther and from the equation (2) 